\title{
Are local Tax Rates Strategic Complements or Strategic Substitutes?
}

\author{
Online Appendix
}

RAPHÄ̈L PARCHET

\section{A Database on income tax rates at the municipality level in Switzerland}

\section{A.1 Personal income taxation}

Personal income taxes in Switzerland are residence-based. Deductions and exemptions for the definition of the taxable income, as well as a complete tax schedule is set at the cantonal level and may vary according to the personal status of the taxpayer and its income. Cantons fix annually a multiplier applied to the basic statutory tax rate, thus determining the amount due to the canton.

Municipalities decide on a municipal tax multiplier that applies to a basic statutory tax rate that is common to all municipalities in the canton (but that may differ from the cantonal basic statutory tax rate). Municipal multipliers are fixed annually by municipal parliaments. In a some cantons, the municipal multiplier encompasses multiple multipliers set by school district or other municipal sub-entities. In a majority of cantons, parishes are also allowed to set their own tax multiplier. In general, parish jurisdictional borders coincide with municipal borders, although some exceptions exist (see Section A.2.1 below).

Consolidated cantonal, municipal and church tax rates, levied for a given taxpayer and income level, can thus be decomposed as follows:

$$
T_{i, j, c} \equiv \underbrace{\tau_{c} \times M_{c}}_{t_{c}}+\underbrace{\tau_{m, c} \times M_{i, c}}_{t_{i, c}}+\underbrace{\tau_{p, c} \times M_{j, c}}_{t_{j, c}}
$$

where

- $t_{c} \equiv \tau_{c} \times M_{c}$ is the cantonal tax rate of canton $c . \tau_{c}$ is a basic statutory tax rate derived from the cantonal tax schedule. $M_{c}$ is the cantonal multiplier that applies to the basic statutory tax rate and determines the amount due to the canton. In some cantons, $M_{c}$ is fixed and equal to $100 \%$.

- $t_{i, c} \equiv \tau_{m, c} \times M_{i, c}$ is the municipal tax rate of municipality $i . M_{i, c}$ is the municipal tax multiplier that applies to a basic statutory tax rate $\tau_{m, c}$. This basic statutory tax rate is common to all municipalities in the canton and may not be the same as $\tau_{c}$. 
- $t_{j, c} \equiv \tau_{p, c} \times M_{j, c}$ is the church tax rate of the parish $j . \quad M_{j, c}$ is the church tax multiplier and $\tau_{p, c}$ is the basic statutory tax rate common to all parishes in the canton. $\tau_{p, c}$ may not be the same as $\tau_{m, c}$ or $\tau_{c}$. $t_{j, c}$ depends on the religion of the taxpayer. In some cantons $t_{j, c}=0$.

In a majority of cantons, $\tau_{c}=\tau_{m, c}=\tau_{p, c}=\tau$ such that equation (1) becomes

$$
T_{i, j, c} \equiv \tau\left(M_{c}+M_{i, c}+M_{j, c}\right) \quad .
$$

\section{A.2 Predicted income tax rates}

\section{A.2.1 Methodology}

Consolidated cantonal plus municipal plus church tax rates are published annually by the Swiss Federal Tax Administration for a sample of the largest municipalities. ${ }^{1}$ These tax rates are defined as shares, at the municipal level, of the consolidated cantonal, municipal and church tax liability in gross annual income for different categories of taxpayers (unmarried, married without children, married with two children, retired) and income classes (up to CHF 1,000,000).

I compute consolidated tax rates at municipal level for all municipalities in Switzerland between 1983 and 2012 using consolidated tax rates for the sample of municipalities in official statistics and municipal and church tax multipliers that I collected for all municipalities. I follow a two-step procedure. First, $t_{c}, \tau_{m, c}$ and $\tau_{p, c}$ are estimated by a linear regression of $T_{i, c}$ on $M_{i, c}$ and $M_{j, c}$ for each canton, year, type of taxpayers and income level, separately, using data for the sample of municipalities available in the official statistics. The estimated equation can be written as

$$
T_{i}=\alpha+\beta_{m} M_{i}+\beta_{p} M_{j}+\varepsilon_{i}
$$

such that $\hat{\alpha}=t_{c}, \hat{\beta_{m}}=\tau_{m, c}$, and $\hat{\beta_{p}}=\tau_{p, c}$.

In the case where $\tau_{c}=\tau_{m, c}=\tau_{p, c}=\tau$, equation (3) is equivalent to

$$
T_{i}=\alpha+\beta\left(M_{i}+M_{j}\right)+\varepsilon_{i}
$$

Second, consolidated tax rates for each year, type of taxpayers and income level are predicted for all municipalities using their municipal and church tax multipliers.

Predictions are, in theory, perfect (i.e., $\left.\varepsilon_{i}=0\right)$ ). In practice, however, small prediction errors can occur for the following reasons :

- In general, parish jurisdictional borders coincide with municipal borders and one parish encompasses one or more municipalities such that each municipality has one corresponding church multiplier. If borders do not coincide or if there exists more than one parish per municipality, I approximate the corresponding church multiplier for a municipality $i$ by taking the average church multipliers of the parishes in its territory.

- Church tax rates depend on the religion of the taxpayer. There are two predominant churches in Switzerland: the Protestant and the Roman Catholic church. I use for each parish the multiplier of the religion of the majority of the population in the municipality according to the population census of $2000 .^{2}$

\footnotetext{
${ }^{1}$ The data can be accessed here: https://www.estv.admin.ch/estv/de/home/allgemein/steuerstatistiken.

${ }^{2}$ The information for the population census of 2000 is available only for municipalities that exist in 2012. I replace missing data due to merge of municipalities by the value of the merged municipality.
} 
- Some municipalities encompass multiple sub-entities. If these sub-entities are distinct, I add them up. If there exist multiple sub-entities of the same kind for one municipality (e.g. multiple school districts), I take the average multipliers for the sub-entities and do not use these observations in the estimation of equation (3), except if this is the case for all municipalities in a canton as in $\mathrm{AI}^{3}{ }^{3}$

- The underlying information used by the Federal Tax Administration may differ from the information I collected. This is the case notably for the main religion of the parish or when municipalities or parishes change their multiplier.

- Some multipliers are missing because municipalities have merged during a civil year and the multiplier for the new municipality is not available for that year. I replace the missing multiplier by its value of the year after the merge, and do not use these observations in the estimation of equation (3).

- Prediction errors can also occur because of rounded values of tax rates.

It is easy to detect potential problems in the estimation of equation (3) as we expect a perfect fit. I follow a 5 -step procedure:

1. Estimate equation (3) and compute predicted tax rates.

2. Investigate graphically the regression fit for each canton and year. Drop "obvious" outliers.

3. Re-estimate equation (3) and compute predicted tax rates, prediction errors and Studentized residuals.

4. Drop observations if the prediction error is greater that 0.05 (in absolute value) and the Studentized residual is greater than 2.5 (in absolute value). ${ }^{4}$ These observations are also investigated graphically.

5. Re-estimate equation (3).

\section{A.2.2 Special cases}

There are several special cases that deserve attention:

- This methodology cannot be applied in the cantons of BS, SO (before 1986) and NE (before 2001) because municipalities were allowed to set their own tax schedule. Predicted tax rates can therefore not be computed for these cantons.

- In the cantons of VD and LU, there exists a maximum tax rate that produces a kink in regressions for tax rates on high income levels. The values of these kinks are investigated graphically for all years and categories of taxpayers. Equations (3) are then estimated using only municipalities with a multiplier implying a tax rate below these values. Municipalities with a higher multiplier are predicted a tax rate that equals the value at the kink. If only tax rates above or below the kink are observed, information from previous years are used to predict tax rates that cannot be predicted according to the above methodology.

\footnotetext{
${ }^{3}$ For full canton names, see Table 1 of the Online Appendix.

${ }^{4}$ Studentized residuals may be very large as regressions are close to a perfect fit. I opted therefore to have a double condition. Other values are used in some cantons (see Online Appendix Table ??). This step is not applied for AI and AR.
} 
Table 1 - Data on municipal and church tax multipliers

\begin{tabular}{|c|c|c|c|c|c|c|c|}
\hline Canton & & $\begin{array}{c}\text { Tax mult. } \\
\text { available since }\end{array}$ & Tax system & $\begin{array}{l}\text { Majority confession } \\
\text { in municipalities }\end{array}$ & $\begin{array}{r}\text { Estir } \\
\text { Ma } \\
\end{array}$ & $\begin{array}{l}(3)-(5) \\
\text { value }\end{array}$ & $\begin{array}{l}\text { Max. pred. } \\
\text { error }\end{array}$ \\
\hline Aargau & $(\mathrm{AG})$ & 1983 & $\tau_{m, c}=\tau_{p, c}$ & Roman-Catholic \& Protestant ${ }^{1}$ & 0.05 & 2.5 & 0.1 \\
\hline Appenzell Ausserrhoden & $(\mathrm{AR})$ & 1983 & $\tau_{m, c}=\tau_{p, c}$ & Protestant & $\mathrm{n} / \mathrm{a}$ & $\mathrm{n} / \mathrm{a}$ & 0 \\
\hline Appenzell Innerrhoden & $(\mathrm{AI})$ & 2001 & $\tau_{m, c}=\tau_{p, c}$ & Roman-Catholic & $\mathrm{n} / \mathrm{a}$ & $\mathrm{n} / \mathrm{a}$ & 0.4 \\
\hline Basel-Landschaft & $(\mathrm{BL})$ & 1983 & $\tau_{m, c} \neq \tau_{p, c}$ & Roman-Catholic \& Protestant $^{1}$ & 0.5 & 3 & 0.1 \\
\hline Bern & $(\mathrm{BE})$ & 1983 & $\tau_{m, c} \neq \tau_{p, c}$ & Roman-Catholic \& Protestant ${ }^{1}$ & 0.05 & 2.5 & 0 \\
\hline Fribourg & $(\mathrm{FR})$ & 1983 & $\tau_{m, c}=\tau_{p, c}$ & Roman-Catholic \& Protestant ${ }^{2}$ & 0.05 & 2.5 & 0 \\
\hline Geneva & $(\mathrm{GE})$ & 1983 & $\begin{array}{c}\tau_{m, c}=\tau_{p, c} \\
t_{p, c}=0\end{array}$ & & 0.1 & 3 & 0 \\
\hline Glarus & $(\mathrm{GL})$ & 1983 & $\tau_{m, c}=\tau_{p, c}$ & Roman-Catholic \& Protestant & 0.05 & 2.5 & 0 \\
\hline Graubünden & $(\mathrm{GR})$ & 1983 & $\tau_{m, c}=\tau_{p, c}$ & Roman-Catholic \& Protestant & 0.5 & 3 & 0.4 \\
\hline Jura & $(\mathrm{JU})$ & 1983 & $\tau_{m, c} \neq \tau_{p, c}$ & Roman-Catholic & 0.05 & 2.5 & 0 \\
\hline Luzern & $(\mathrm{LU})$ & 1983 & $\tau_{m, c}=\tau_{p, c}$ & Roman-Catholic & 0.05 & 2.5 & 0 \\
\hline Neuchâtel & $(\mathrm{NE})$ & $2001^{3}$ & $\begin{array}{c}\tau_{m, c}=\tau_{p, c} \\
t_{p, c}=0\end{array}$ & & 0.05 & 2.5 & 0.2 \\
\hline Nidwalden & $(\mathrm{NW})$ & 1983 & $\tau_{m, c}=\tau_{p, c}$ & Roman-Catholic & 0.05 & 2.5 & 0 \\
\hline Obwalden & $(\mathrm{OW})$ & 1983 & $\tau_{m, c}=\tau_{p, c}$ & Roman-Catholic & 0.05 & 2.5 & 0 \\
\hline Schaffhausen & $(\mathrm{SH})$ & 1983 & $\tau_{m, c}=\tau_{p, c}$ & Roman-Catholic \& Protestant & 0.5 & 3 & 0.1 \\
\hline Schwyz & $(\mathrm{SZ})$ & 1983 & $\tau_{m, c}=\tau_{p, c}$ & Roman-Catholic & 0.05 & 2.5 & 0 \\
\hline Solothurn & $(\mathrm{SO})$ & $1986^{4}$ & $\tau_{m, c}=\tau_{p, c}$ & Roman-Catholic \& Protestant $^{2}$ & 0.05 & 2.5 & 0 \\
\hline St. Gallen & $(\mathrm{SG})$ & 1983 & $\tau_{m, c}=\tau_{p, c}$ & Roman-Catholic \& Protestant ${ }^{2}$ & 0.05 & 2.5 & 0 \\
\hline Thurgau & $(\mathrm{TG})$ & 1983 & $\tau_{m, c}=\tau_{p, c}$ & Roman-Catholic \& Protestant ${ }^{2}$ & 0.05 & 2.5 & 0 \\
\hline Ticino & (TI) & 1983 & $\begin{aligned} \tau_{m, c} & =\tau_{p, c} \\
t_{p, c} & =0^{5}\end{aligned}$ & & 0.05 & 2.5 & 0 \\
\hline Uri & $(\mathrm{UR})$ & 1983 & $\tau_{m, c} \neq \tau_{p, c}$ & Roman-Catholic & 0.05 & 2.5 & 0 \\
\hline Valais & (VS) & 1983 & $\begin{aligned} \tau_{m, c} & =\tau_{p, c} \\
t_{p, c} & =0^{6}\end{aligned}$ & & 0.5 & 3 & 0.2 \\
\hline Vaud & $(\mathrm{VD})$ & 1983 & $\begin{array}{c}\tau_{m, c}=\tau_{p, c} \\
t_{p, c}=0\end{array}$ & & 0.1 & 3 & 0 \\
\hline Zug & $(\mathrm{ZG})$ & 1983 & $\tau_{m, c}=\tau_{p, c}$ & Roman-Catholic & 0.05 & 2.5 & 0 \\
\hline Zürich & $(\mathrm{ZH})$ & 1983 & $\tau_{m, c}=\tau_{p, c}$ & Roman-Catholic \& Protestant ${ }^{1}$ & 0.05 & 2.5 & 0 \\
\hline
\end{tabular}

- In the cantons of AI, BL, GR and SH, church multipliers are not available for all years. Tax rates can still be accurately predicted by estimating the following regression:

$$
T_{i}=\alpha+\beta M_{i}+u_{i}
$$

In this case, $\hat{\alpha}=t_{c}+\bar{t}_{j}$. Prediction quality is checked following the same 5-step procedure as described above but using a prediction error of 0.5 and a Studentized residual of 3 in step 4 .

- In some cantons, the estimation of equations (3) or (5) is less precise because of some caveats affecting all municipalities in the canton:

- AI: multipliers are the average of municipal sub-entities for all municipalities.

- AR, 1982-1987: the available church multiplier is the average of the multipliers for Protestants and Roman-Catholics.

- VS, all municipalities fix a inflation-adjustment index besides their multiplier.

Online Appendix Table 1 summarizes for each canton the main information on municipal and church tax multipliers availability and on tax rate predictions. 


\section{B Model derivation}

This appendix details the derivation of the model presented in Section IV of the paper. The economy is populated by an unit mass of identical individuals with exogenous income $w$ and preference $U(c, g)$ over a private consumption good $c$ and a locally-provided public good $g$. The utility function $U(c, g)$ is continuous, twice continuously differentiable in $c$ and $g$, strictly quasi-concave and the marginal rate of substitution between $c$ and $g$ is decreasing in $g$. Individuals choose where to reside among $J$ identical jurisdictions. In each jurisdiction $j$, the locally-provided public good $g_{j}$ is financed by a residence-based linear income tax $t_{j}$ levied on the $N_{j}$ jurisdiction's residents.

Local governments use total tax revenue $R_{j}=t_{j} N_{j} w$ to produce a local public good. The costs of providing the local public good (in units of the private consumption good) is given by a cost function $C\left(g_{j}, N_{j}\right)$ that depends on the level of the public good and the number of residents in jurisdiction $j$. The government budget constraint is

$$
C\left(g_{j}, N_{j}\right) \leq t_{j} N_{j} w
$$

There are economies of scale with respect to the level of public good whenever $\frac{C\left(g_{j}, N_{j}\right)}{g_{j}}>$ $C_{g}$ and economies of population scale whenever $\frac{C\left(g_{j}, N_{j}\right)}{N_{j}}>C_{N}$ where $C_{g} \equiv \frac{\partial C\left(g_{j}, N_{j}\right)}{\partial g_{j}}$ and $C_{N} \equiv \frac{\partial C\left(g_{j}, N_{j}\right)}{\partial N_{j}}$ are the marginal costs with respect to the level of public good and the number of residents, respectively. Marginal costs are assumed to be constant such that the economies of scale (if present) are never exhausted and that there is a one-to-one mapping between a given level of public good, the number of residents and the costs of providing the public good. The local government chooses the tax policy $t_{j}$ that satisfies the budget constraint with equality and that is supported by a majority of the residents, anticipating the location decisions of the individuals and taking the tax rate of the other jurisdictions as given.

\section{B.1 Location decisions}

Individuals have idiosyncratic preferences over locations. An individual $i$, if she decides to live in jurisdiction $j$, has indirect utility given by

$$
V_{i j}=U\left(c_{j}\left(t_{j}\right), g_{j}\left(t_{j}\right)\right)+x_{i j}
$$

where $U\left(c_{j}\left(t_{j}\right), g_{j}\left(t_{j}\right)\right)$ is the valuation of living in jurisdiction $j$ common to all individuals and $x_{i j}$ is the idiosyncratic valuation of location $j$. Note that according to individual's budget constraint, $c_{j}\left(t_{j}\right)=\left(1-t_{j}\right) w$ and tax rates are chosen such that equation $(6)$ is satisfied with equality in every jurisdiction. In what follows, the utility function is assumed to be such that $\frac{\partial V_{i j}}{\partial t_{j}}<0 .{ }^{5}$

Individual $i$ locates in the location $j$ that gives her higher utility than any other location $j^{\prime}$. Assuming that individiduals have idiosyncratic valuation over location distributed extreme value with variance $\frac{\pi^{2}}{6}$, the fraction $N_{j}$ of individuals living in jurisdiction $j$ is given by

$$
N_{j}\left(t_{j}, t_{-j}\right)=\frac{\exp V_{j}}{\sum_{i} \exp V_{i}}
$$

\footnotetext{
${ }^{5}$ In other words, the valuation of the public good is not strong enough for individuals to prefer higher tax rates.
} 
Therefore,

$$
\begin{aligned}
\frac{\partial N_{j}}{\partial t_{j}} & =\frac{\exp V_{j} \frac{\partial V_{j}}{\partial t_{j}}\left[\sum_{i} \exp V_{i}\right]-\exp V_{j} \frac{\partial}{\partial t_{j}}\left[\sum_{i} \exp V_{i}\right]}{\left[\sum_{i} \exp V_{i}\right]^{2}} \\
& =N_{j}\left[\frac{\partial V_{j}}{\partial t_{j}}-\frac{\sum_{i \neq j} \exp V_{i} \frac{\partial V_{i}}{\partial t_{j}}+\exp V_{j} \frac{\partial V_{j}}{\partial t_{j}}}{\sum_{i} \exp V_{i}}\right] \\
& =N_{j}\left[\left(1-N_{j}\right) \frac{\partial V_{j}}{\partial t_{j}}-\sum_{i \neq j} N_{i} \frac{\partial V_{i}}{\partial t_{j}}\right] \\
& =N_{j}\left(1-N_{j}\right)\left[\frac{\partial V_{j}}{\partial t_{j}}-\frac{\partial V_{-j}}{\partial t_{j}}\right]<0,
\end{aligned}
$$

Where the last line uses the symmetry $\frac{\partial V_{i}}{\partial t_{j}}=\frac{\partial V_{k}}{\partial t_{j}} \forall i, k \neq j$ and $\sum_{i \neq j} N_{i}=1-N_{j}$. Similarly,

$$
\begin{aligned}
\frac{\partial N_{j}}{\partial t_{-j}} & =\frac{\exp V_{j} \frac{\partial V_{j}}{\partial t_{-j}}\left[\sum_{i} \exp V_{i}\right]-\exp V_{j} \frac{\partial}{\partial t_{-j}}\left[\sum_{i} \exp V_{i}\right]}{\left[\sum_{i} \exp V_{i}\right]^{2}} \\
& =N_{j}\left[\frac{\partial V_{j}}{\partial t_{-j}}-N_{-j} \frac{\partial V_{-j}}{\partial t_{-j}}-\sum_{i \neq-j} N_{i} \frac{\partial V_{i}}{\partial t_{-j}}\right] \\
& =N_{j}\left[\frac{\partial V_{j}}{\partial t_{-j}}\left(1-\left(1-N_{-j}\right)\right)-N_{-j} \frac{\partial V_{-j}}{\partial t_{-j}}\right] \\
& =N_{j} N_{-j}\left[\frac{\partial V_{j}}{\partial t_{-j}}-\frac{\partial V_{-j}}{\partial t_{-j}}\right] \\
& =-N_{j} N_{-j}\left[\frac{\partial V_{-j}}{\partial t_{-j}}-\frac{\partial V_{j}}{\partial t_{-j}}\right]>0 .
\end{aligned}
$$

Note that $\frac{\partial N_{j}}{\partial t_{-j}}=-\frac{N_{-j}}{\left(1-N_{j}\right)} \frac{\partial N_{j}}{\partial t_{j}}$ by symmetry. Then,

$$
\begin{aligned}
\frac{\partial^{2} N_{j}}{\partial t_{j} \partial t_{-j}} & =N_{j}\left(1-N_{j}\right) \underbrace{\left[\frac{\partial^{2} V_{j}}{\partial t_{j} \partial t_{-j}}-\frac{\partial^{2} V_{-j}}{\partial t_{j} \partial t_{-j}}\right]}_{=0}+\left[\frac{\partial V_{j}}{\partial t_{j}}-\frac{\partial V_{-j}}{\partial t_{j}}\right]\left[\frac{\partial N_{j}}{\partial t_{-j}}\left(1-2 N_{j}\right)\right] \\
& =-\left[\frac{\partial V_{j}}{\partial t_{j}}-\frac{\partial V_{-j}}{\partial t_{j}}\right]^{2} N_{j} N_{-j}\left(1-2 N_{j}\right) \leq 0 .
\end{aligned}
$$

and

$$
\begin{aligned}
\frac{\partial^{2} N_{j}}{\partial t_{j}^{2}} & =N_{j}\left(1-N_{j}\right)\left[\frac{\partial^{2} V_{j}}{\partial t_{j}^{2}}-\frac{\partial^{2} V_{-j}}{\partial t_{j}^{2}}\right]+\left[\frac{\partial V_{j}}{\partial t_{j}}-\frac{\partial V_{-j}}{\partial t_{j}}\right] \frac{\partial N_{j}}{\partial t_{j}}\left(1-2 N_{j}\right) \\
& =N_{j}\left(1-N_{j}\right)\left[\frac{\partial^{2} V_{j}}{\partial t_{j}^{2}}-\frac{\partial^{2} V_{-j}}{\partial t_{j}^{2}}+\left(1-2 N_{j}\right)\left[\frac{\partial V_{j}}{\partial t_{j}}-\frac{\partial V_{-j}}{\partial t_{j}}\right]^{2}\right] \gtrless 0 .
\end{aligned}
$$

I assume $\frac{\partial^{2} N_{j}}{\partial t_{j}^{2}}<0$ such that the number of residents is a concave function of the tax rate. This ensures that the elasticity of the population with respect to tax rates increases (in absolute value) with tax rates, which is consistent with a Laffer-curve intuition. Note also that, if $J=2$ and jurisdictions are symmetric, $N_{j}=N_{-j}=\frac{1}{2}$. Then, $\frac{\partial N_{j}}{\partial t_{-j}}=-\frac{\partial N_{j}}{\partial t_{j}}$, $\frac{\partial^{2} N_{j}}{\partial t_{j} \partial t_{-j}}=0$ and $\frac{\partial^{2} N_{j}}{\partial t_{j}^{2}}=\frac{1}{4}\left[\frac{\partial^{2} V_{j}}{\partial t_{j}^{2}}-\frac{\partial^{2} V_{-j}}{\partial t_{j}^{2}}\right]$. 


\section{B.2 Local governments}

In each jurisdiction $j$, the local government anticipates the effect of its tax policy on its own tax base and maximizes the utility of the representative resident, taking the tax policy in the other jurisdictions as fixed.

The marginal payoff function $(M P F)$ of jurisdiction $j$ is given by the maximization of the following Lagrangean function

$$
L\left(t_{j}, g_{j}\right)=U\left(\left(1-t_{j}\right) w, g_{j}\right)+\lambda\left(t_{j} N_{j} w-C\left(N_{j}, g_{j}\right)\right)
$$

where $\lambda$ is the Lagrange multiplier. The first order conditions for $t_{j}$ and $g_{j}$ are, respectively,

$$
\begin{aligned}
& 0=-w U_{c}+\lambda\left(w\left(N_{j}+t_{j} \frac{\partial N_{j}}{\partial t_{j}}\right)-C_{N} \frac{\partial N_{j}}{\partial t_{j}}\right), \\
& 0=U_{g}-\lambda C_{g} .
\end{aligned}
$$

Solving for $\lambda$ and combining equations (7) and (8) yields

$$
\begin{aligned}
0 & =-w U_{c}+\frac{U_{g}}{C_{g}}\left(w\left(N_{j}+t_{j} \frac{\partial N_{j}}{\partial t_{j}}\right)-C_{N} \frac{\partial N_{j}}{\partial t_{j}}\right) \\
0 & =w\left[-U_{c}+\frac{U_{g}}{C_{g}}\left(N_{j}+\frac{\partial N_{j}}{\partial t_{j}}\left(t_{j}-\frac{C_{N}}{w}\right)\right)\right] \\
0 & =w\left[-U_{c}+\frac{U_{g}}{C_{g}} N_{j}\left(1-\varepsilon_{j}\left(1-\frac{C_{N}}{t_{j} w}\right)\right)\right] \\
0 & =w\left[-U_{c}+\frac{U_{g}}{C_{g}} N_{j}\left(1-\varepsilon_{j}\left(1-\frac{C_{N} N_{j}}{C\left(N_{j}, g_{j}\right)}\right)\right)\right],
\end{aligned}
$$

where $\varepsilon_{j} \equiv-\frac{\partial N_{j}}{\partial t_{j}} \frac{t_{j}}{N_{j}}>0$. The last lines uses the government budget constraint $C\left(N_{j}, g_{j}\right)=$ $t_{j} N_{j} w \Leftrightarrow t_{j} w=\frac{C\left(N_{j}, g_{j}\right)}{N_{j}}$.

Equation (9) defines a tax reaction function for each jurisdiction, given the tax rate of the other jurisdictions. In equilibrium, optimal tax rates satisfy in each jurisdiction $j$

$$
N_{j} \frac{U_{g}}{U_{c}}=C_{g}\left(\frac{1}{1-\varepsilon_{j}\left(1-\frac{C_{N} N_{j}}{C\left(N_{j}, g_{j}\right)}\right)}\right) .
$$

Note that $\frac{1}{1-\varepsilon_{j}\left(1-\frac{C_{N} N_{j}}{C\left(N_{j}, g_{j}\right)}\right)}$ defines a mark-up over the marginal cost in the production of the local public good. Equilibrium tax rates are too low with respect to the social optimum at which the marginal rate of substitution between the public and the private goods equals the marginal cost.

This result of the underprovision of the local public good does not depend on the presence of scale economies in the production of the local public good. It depends, however, on the presence of scale economies with respect to the number of residents. The local public good is provided at the socially efficient level if its per-user cost is constant, $\frac{C\left(N_{j}, g_{j}\right)}{N_{j}}=C_{N}$ (in a model with identical income). The local public good is under-provided if there are economies of scale with respect to the number of residents served, $\frac{C\left(N_{j}, g_{j}\right)}{N_{j}}>C_{N} \cdot{ }^{6}$ In the

\footnotetext{
${ }^{6}$ In the case of diseconomies of scale with respect to the number of residents, the local public good will be overprovided. I focus here on non-decreasing economies of scale only.
} 
standard case of a pure local public good (absence of congestion), $C_{N}=0$, and the local public good is underprovided. In this last case, the mark-up over the marginal production cost reduces to $\frac{1}{1-\varepsilon_{j}}$.

Tax rates are strategic complements or strategic subsitutes depending on how the marginal payoff function, given by the right-hand side of equation (9), varies with the tax rates of the other jurisdictions. That is, tax rates are strategic substitutes if $\frac{\partial M P F}{\partial t_{-j}}<0$.

We have,

$$
\begin{aligned}
\frac{\partial M P F}{\partial t_{-j}} & =w\left[\frac{U_{g}}{C_{g}}\left(\frac{\partial N_{j}}{\partial t_{-j}}+\frac{\partial^{2} N_{j}}{\partial t_{j} \partial t_{-j}}\left(t_{j}-\frac{C_{N}}{w}\right)\right)+\frac{U_{g g}}{C_{g}} \frac{\partial g}{\partial t_{-j}}\left(N_{j}+\frac{\partial N_{j}}{\partial t_{j}}\left(t_{j}-\frac{C_{N}}{w}\right)\right)\right] \\
& =w \frac{U_{g}}{C_{g}}\left[\frac{\partial^{2} N_{j}}{\partial t_{j} \partial t_{-j}} t_{j}\left(1-\frac{C_{N}}{t_{j} w}\right)+\frac{\partial N_{j}}{\partial t_{-j}}+\frac{U_{g g}}{U_{g}} \frac{\partial g}{\partial t_{-j}} N_{j}\left(1-\varepsilon_{j}\left(1-\frac{C_{N}}{t_{j} w}\right)\right)\right] .
\end{aligned}
$$

Differentiating the government budget constraint $t_{j} N_{j} w=C\left(N_{j}, g_{j}\right)$ with respect to $t_{-j}$ gives:

$$
t_{j} w \frac{\partial N}{\partial t_{-j}}=C_{N} \frac{\partial N}{\partial t_{-j}}+C_{g} \frac{\partial g}{\partial t_{-j}}
$$

Thus,

$$
\frac{\partial g}{\partial t_{-j}}=\frac{t_{j} w}{C_{g}} \frac{\partial N}{\partial t_{-j}}\left(1-\frac{C_{N}}{t_{j} w}\right)
$$

and

$$
\begin{aligned}
\frac{\partial M P F}{\partial t_{-j}} & =w \frac{U_{g}}{C_{g}}\left[\frac{\partial^{2} N_{j}}{\partial t_{j} \partial t_{-j}} t_{j}\left(1-\frac{C_{N}}{t_{j} w}\right)+\frac{\partial N_{j}}{\partial t_{-j}}+\frac{t_{j} N_{j} w}{C_{g}} \frac{U_{g g}}{U_{g}} \frac{\partial N}{\partial t_{-j}}\left(1-\frac{C_{N}}{t_{j} w}\right)\left(1-\varepsilon_{j}\left(1-\frac{C_{N}}{t_{j} w}\right)\right)\right] \\
& =w \frac{U_{g}}{C_{g}}[\underbrace{\frac{\partial^{2} N_{j}}{\partial t_{j} \partial t_{-j}} t_{j}\left(1-\frac{C_{N}}{t_{j} w}\right)}_{\leq 0}+\frac{\partial N_{j}}{\partial t_{-j}}[1+\underbrace{\frac{U_{g g}}{U_{g}} \frac{C(g, N)}{C_{g}}\left(1-\frac{C_{N}}{t_{j} w}\right)\left(1-\varepsilon_{j}\left(1-\frac{C_{N}}{t_{j} w}\right)\right)}_{<0 \text { as } U_{g g}<0}]] .
\end{aligned}
$$

A sufficient condition for tax rates to be strategic substitutes is

$$
\left|\frac{\frac{C(g, N)}{g_{j}}}{C_{g}} \frac{U_{g g}}{U_{g}} g\left(1-\frac{C_{N} N_{j}}{C\left(N_{j}, g_{j}\right)}\right)\left(1-\varepsilon_{j}\left(1-\frac{C_{N} N_{j}}{C\left(N_{j}, g_{j}\right)}\right)\right)\right|>1 .
$$

where $\left(1-\varepsilon_{j}\left(1-\frac{C_{N} N_{j}}{C\left(N_{j}, g_{j}\right)}\right)\right)=\frac{\partial R_{j}}{\partial t_{j}} \frac{t_{j}}{R_{j}}$ is the elasticity of the tax revenue with respect to $t_{j} ; \frac{C(g, N)}{C_{g} g_{j}}\left(1-\frac{C_{N} N_{j}}{C\left(N_{j}, g_{j}\right)}\right)=\frac{\partial g_{j}}{\partial R_{j}} \frac{R_{j}}{g_{j}}$ is the elasticity of the public good provision with respect to the tax revenue, and $\frac{U_{g g}}{U_{g}} g$ is the elasticity of the marginal utility of the public good with respect to the level of public good.

Tax rates are strategic substitutes if the decrease in the marginal utility of the public good due to a higher tax rate is more than proportional to the change in the tax rate, that is, if

$$
\varepsilon_{U_{g}, t_{j}}>1
$$

where $\varepsilon_{U_{g}, t_{j}} \equiv-\frac{\partial R_{j}}{\partial t_{j}} \frac{t_{j}}{R_{j}} \times \frac{\partial g_{j}}{\partial R_{j}} \frac{R_{j}}{g_{j}} \times \frac{\partial U_{g}}{\partial g_{j}} \frac{g_{j}}{U_{g}}=\frac{\partial U_{g}}{\partial t_{j}} \frac{t_{j}}{U_{g}}$ is the elasticity of the marginal utility of the public good with respect to $t_{j}$. 
Interestingly, in the presence of congestion, the likelihood of tax rates as strategic substitutes increases monotonically with the economies of population scale (as long as the elasticity of the tax base is not too high). Specifically, condition (11) can be rewritten as

$$
\left|\frac{\frac{C(g, N)}{g_{j}}}{C_{g}} \frac{U_{g g}}{U_{g}} g_{j}\right|>\frac{1}{\left(1-\frac{C_{N} N_{j}}{C\left(N_{j}, g_{j}\right)}\right)\left(1-\varepsilon_{j}\left(1-\frac{C_{N} N_{j}}{C\left(N_{j}, g_{j}\right)}\right)\right)},
$$

where the right-hand side of the condition decreases monotonically with $\left(1-\frac{C_{N} N_{j}}{C\left(N_{j}, g_{j}\right)}\right)$ as long as $\varepsilon_{j}\left(1-\frac{C_{N} N_{j}}{C\left(N_{j}, g_{j}\right)}\right)<0.5$.

\section{Model intuition}

To form intuition, I concentrate on the two-jurisdiction, pure public good case for which the above condition is the least likely to be satisfied. In this case, $C_{N}=0$ (therefore $\left.\sigma_{j}=0\right)$ and $N_{j}=N_{-j}=0.5$ and $\frac{\partial^{2} N_{j}}{\partial t_{j} \partial t_{-j}}=0$.

Then, the marginal payoff function (equation 9) becomes

$$
w\left[-U_{c}+\frac{U_{g}}{C_{g}} N_{j}\left(1-\varepsilon_{j}\right)\right],
$$

where $w N_{j}\left(1-\varepsilon_{j}\right)=\frac{\partial R_{j}}{\partial t_{j}}$ is the marginal revenue of the tax policy (taking into account residents' mobility response) and $\frac{U_{g}}{C_{g}}$ is the marginal utility of an increase in the tax revenue through higher public good consumption $\left(\frac{U_{g}}{C_{g}}=\frac{\partial U}{\partial g_{j}} \frac{\partial g_{j}}{\partial R_{j}}=\frac{\partial U}{\partial R_{j}}\right)$. The optimal tax policy, for a given tax rate in the other jurisction, is in fact nothing else that equating the marginal disutility of the tax in terms of lower private consumption with its marginal utility in terms of higher public good consumption.

How does an increase in the tax policy of the neighboring jurisdiction change the optimal tax policy of jurisdiction $j$ ? It depends on its effect on jurisdiction $j$ 's marginal payoff function:

$$
\begin{aligned}
& \frac{\partial M P F}{\partial t_{-j}}=\frac{U_{g}}{C_{g}} \frac{\partial}{\partial t_{-j}}\left[w N_{j}\left(1-\varepsilon_{j}\right)\right]+w N_{j}\left(1-\varepsilon_{j}\right) \frac{1}{C_{g}} \frac{\partial U_{g}}{\partial t_{-j}} \\
& \frac{\partial M P F}{\partial t_{-j}}=\frac{U_{g}}{C_{g}}\left[w \frac{\partial N_{j}}{\partial t_{-j}}+w N_{j}\left(1-\varepsilon_{j}\right) \frac{U_{g g}}{U_{g}} \frac{\partial g_{j}}{\partial t_{-j}}\right] .
\end{aligned}
$$

The marginal payoff function of jurisdiction $j$ depends on $t_{-j}$ through how the latter affects jurisdiction $j$ 's number of residents. This has two opposite effects. First, an increase in $t_{-j}$ leads to an increase in $N_{j}$, which increases the marginal revenue of the tax policy in jurisdiction $j$ : the tax policy is worth more in terms of higher marginal revenue because it is applied on a larger tax base. This is captured by the term: $w \frac{\partial N_{j}}{\partial t_{-j}}=\frac{\partial^{2} R_{j}}{\partial t_{j} \partial t_{-j}}>0$. But, the increase in $t_{-j}$ also leads to a higher public good provision in jurisdiction $j$, which decreases its marginal utility: $U_{g g} \frac{\partial g_{j}}{\partial t_{-j}}<0$. Whether the marginal payoff function in jurisdiction $j$ increases or decreases with $t_{-j}$ depends on which of the two effects dominates.

As $\frac{\partial g_{j}}{\partial t_{-j}}$ depends on $\frac{\partial N_{j}}{\partial t_{-j}}$ through the government budget constraint, equation (13) can be rewritten as:

$$
\frac{\partial M P F}{\partial t_{-j}}=w \frac{\partial N_{j}}{\partial t_{-j}} \frac{U_{g}}{C_{g}}\left[1+\left(1-\varepsilon_{j}\right) \frac{\frac{C(g, N)}{g_{j}}}{C_{g}} \frac{U_{g g}}{U_{g}} g\right] .
$$


Therefore,

$$
\frac{\partial M P F}{\partial t_{-j}}=w \frac{\partial N_{j}}{\partial t_{-j}} \frac{U_{g}}{C_{g}}\left[1-\varepsilon_{U_{g}, t_{j}}\right]
$$

When a neighboring jurisdiction increases its tax rate, it increases the marginal revenue of the tax policy of jurisdiction $j$, which, then, has an incentive to change its tax policy. But increasing the tax rates and therefore providing more public good has a negative effect on the marginal utility of the latter. Tax rates are strategic complement or strategic substitutes depending on whether the decrease in the marginal utility of the public good is less or more than proportional to the change in the tax rate. 